Original article

\title{
Assessment of burden of internet addiction and its association with quality of sleep and cardiovascular autonomic function in undergraduate medical students
}

\author{
Amrita Nayak ${ }^{a}$, Kuppusamy Saranya ${ }^{\text {b, }}$, Jean Fredrick ${ }^{c}$, Ramachandran Madumathy ${ }^{\text {, }}$ \\ Senthil Kumar Subramanian ${ }^{\mathrm{e}}$ \\ a JIPMER, Puducherry, India \\ ${ }^{\mathrm{b}}$ Department of Physiology, JIPMER, Puducherry, India \\ ${ }^{\mathrm{c}}$ Department of Physiology, Mahatma Gandhi Medical College and Research Institute, Sri Balaji Vidyapeeth (Deemed to be University), Puducherry, India \\ d Department of Physiology, AIIMS, Bhubaneshwar, India \\ e Department of Physiology, All India Institute of Medical Sciences, Mangalagiri, Andhra Pradesh, India
}

\section{A R T I C L E I N F O}

\section{Keywords:}

Internet addiction

Medical students

Sleep quality

Sympathetic modulation

\begin{abstract}
A B S T R A C T
Problem considered: This study aimed to determine the association of internet addiction with poor sleep quality and autonomic function in medical students.

Methods: In this cross-sectional study design, we assessed internet addiction, sleep quality, demographic and basal cardiovascular parameters (blood pressure and heart rate), autonomic indices (E: I ratio and isometric handgrip test $\left(\triangle \mathrm{DBP}_{\text {ihg }}\right)$ in 148 medical students. Sleep quality and internet usage were assessed using questionnaires. Qualitative data were expressed in number (percentage) and analyzed using the Chi-square test. Normally distributed quantitative data were analyzed using student t-test and expressed as mean and SD. Logistic regression analysis was done to determine the association between sleep quality and internet addiction. p-value of $<0.05$ was considered to be significant.

Results: In the present study, $64.9 \%$ of participants reported moderate internet usage, and $19.6 \%$ reported excessive internet usage. The preference for internet usage at night-time was more than daytime. Further, the internet addicted group demonstrated increased resting heart rate. We also observed a significant association between internet addiction and sleep quality.

Conclusion: These findings of the present study show that internet overuse is associated with poor sleep quality in undergraduate medical students.
\end{abstract}

\section{Introduction}

The internet today has become an indispensable component of education, entertainment, business, and telecommunication. The use of the internet to achieve a definite goal, for an appropriate amount of time, without psychological or physical discomfort, is termed as healthy internet usage. ${ }^{1}$ The capability of various individuals to limit their use of the internet to appropriate times varies. A negative impact on health is observed in several individuals who cannot limit their usage of internet. This excessive internet usage has led to the emergence of the term "Internet Addiction" (IA) or pathological internet usage. ${ }^{2}$ The advent of smartphones with internet access further worsens the scenario.

Apart from the beneficial aspect, excessive internet usage can deteriorate the individual's physical well being, psychological health and academic domains. ${ }^{3,4}$ IA has an adverse effect on the quality of sleep and increases the incidence of depression symptoms. Poor sleep quality in IA has been documented to be a mediator for physical, psychological and cognitive dysfunctions. On the other hand, poor sleep quality is a key determinant of cardiovascular risk in apparently healthy individuals, such as hypertension. An autonomic disturbance with enhanced adrenergic and decreased vagal tone has been postulated as the plausible link between poor sleep quality and hypertension. ${ }^{5,6}$

\footnotetext{
* Corresponding author.

E-mail addresses: amrita4782@gmail.com (A. Nayak), ktsaran28@gmail.com (K. Saranya), drjeanfredrick@gmail.com (J. Fredrick), Madumathy688@gmail.com (R. Madumathy), senthil.kumar@aiimsmangalagiri.edu.in (S.K. Subramanian).
} 
Adolescents with lesser self-control were reported to be more prone to IA than adults. A cross-sectional study by Krishnamurthy et al. assessed the prevalence of IA and documented that $42.7 \%$ of the medical students were addicted to internet usage. This was thought to be due to their psychological and developmental characteristics, inadequate parental supervision, and unlimited access to the internet. Few studies have been conducted to study IA among medical students. ${ }^{3,7}$ However, the important mechanism linking poor sleep quality and IA is yet to be addressed. Hence, the present study was conceived to examine the link between IA with sleep quality and autonomic function indices among undergraduate medical students.

\section{Methods}

Study design and setting: This was an analytical cross-sectional study conducted in the autonomic function testing (AFT) laboratory, Department of Physiology, JIPMER, Puducherry. The study was conducted under Indian Council of Medical Research Short term Studentship (ICMR STS - 2018) program (Ref no - 2018-02790) for 2 months from August 2018-September 2018. After obtaining approval from the Institute Scientific committee and Ethics committee for human studies (Ref no. JIP/IEC/2018/0150 date 25/05/2018), participants were recruited. The details of the procedure were explained to the participants, and written informed consent was obtained. The confidentiality of the participant details and results was maintained throughout the study.

Participants: 148 (75 males and 73 females) undergraduate medical students (MBBS students - II, III, IV professional year) residing in hostel, in the age group of 18-24 years, in self-reported good health, using the internet for more than one year were recruited. Students with a known history of diabetes mellitus, hypertension, endocrine disorders, psychiatric disorders, and sleep disorders were excluded. Students who are on drugs that affect autonomic functions were also excluded.

Sample size calculation: Assuming the expected proportion of undergraduate students with internet addiction as $43 \%$, alpha error of $5 \%$ (95\% confidence level), and $8 \%$ absolute precision, the sample size calculated was $148 .{ }^{4}$ The sample size was calculated using Open-epi software version 3 .

Parameters measured: Information regarding age, gender, professional year of study was gathered from every participant.

1. Anthropometric parameters: Participant's height was measured to the nearest millimetre by a wall-mounted stadiometer (VM Electronics Hardware Ltd), and weight was measured with a digital weighing machine (Charder Electronic Co. Ltd. Taichung, Taiwan 2013) accurate to the nearest $0.1 \mathrm{~kg}$. BMI was calculated by Quetelet's index. ${ }^{8}$ Waist circumference was measured as the circumference of the abdomen at its narrowest point between the lower costal (10th rib) border and the top of the iliac crest. Hip circumference was measured at the level of greatest posterior protuberance of the buttocks. ${ }^{9}$ Waist Hip ratio was calculated.

2. Assessment of internet addiction using Young's Internet Addiction Test: Details regarding purpose, duration and time preference of internet usage were collected to assess IA using Young's Internet Addiction Test (YIAT-20); a self-administered, 20-item questionnaire, ${ }^{4,5}$ answered in a 5- point Likert scale (0- Does not apply, 1- Rarely, 2- Occasionally, 3-Frequent, 4-Often, 5 Always). Total IA scores are calculated by adding 20 items with possible scores ranging from 0 to 100 . Based on the scoring, subjects were classified into normal users $(\leq 20)$, mild (21-49), moderate (50-79) and severe (80-100) IA groups (score $\leq 20$ - IA absent; score $>20$ - IA present).

3. Assessment of sleep quality by Pittsburgh Sleep Quality Index (PQSI): Sleep quality of the participants was assessed using the PQSI questionnaire. PSQI is a 19-item tool that evaluates sleep quality for a month. It examines the seven components of sleep: sleep quality, sleep latency, sleep duration, sleep efficiency, details of using sleeping pills, and daytime dysfunction. PSQI score range from 0 to 21. A score more than or equal to 5 was considered as poor sleep quality.

4. Baseline cardiovascular parameters: Following $10 \mathrm{~min}$ of rest in supine position, resting heart rate (HR), systolic blood pressure (SBP) and diastolic blood pressure (DBP) were recorded using an automated blood pressure monitor (Omron Healthcare Co. Ltd, Kyoto, Japan).

5. Cardiovascular autonomic reactivity tests: The subjects were explained about the tests. The room temperature at $23^{\circ} \mathrm{C} \pm 2{ }^{\circ} \mathrm{C}$ and the humidity between $25 \%$ and $35 \%$ were maintained. The following cardiovascular autonomic reactivity tests were performed in all the subjects. $^{10,11}$

a) Heart rate response to deep breathing: Parasympathetic activity of the participants was tested by heart rate response to deep breathing. The test was performed in sitting posture with ECG leads connected for Lead II ECG recording. Lead II ECG was acquired at a rate of 1000 samples/second using the BIOPAC MP 150 data acquisition system with Acq Knowledge 3.8.2 software (BIOPAC Inc., Goleta, CA, USA). After $5 \mathrm{~min}$ of sitting, the participants were asked to perform deep breathing at the rate of 6 breaths per minute with inspiratory and expiratory cycles for $5 \mathrm{~s}$ each with continuous Lead II ECG recording. Participants were encouraged to perform deep and maximal respiration synchronized to a voice metronome over $1 \mathrm{~min}$. From the lead II ECG recorded during deep breathing manoeuvre, the RR tachogram was extracted. E: I ratio, the ratio of longest RR interval during expiration to the shortest RR interval during inspiration averaged over 6 cycles of respiration, was computed. E: I ratio depict parasympathetic modulation. ${ }^{11}$

b) Diastolic blood pressure response to sustained isometric handgrip: Sympathetic activity was tested by Diastolic Blood pressure response to Isometric Hand Grip (IHG) manoeuvre. The maximal voluntary contraction (MVC) during sustained isometric handgrip by the participants was measured using a handgrip dynamometer (Inco, Ambala, India). Then the participants were instructed to sustain the handgrip at one-third of their MVC for 3 min. The maximum DBP attained during the manoeuvre was recorded. After the procedure, BP and HR were measured after 2 min to confirm if they have returned to basal levels. During the IHG test, the magnitude of DBP rise during the manoeuvre given as $\triangle \mathrm{DBP}_{\text {ing }}$ (difference between this highest DBP recorded during sustained handgrip and baseline DBP) was calculated. The $\triangle \mathrm{DBP}_{\text {ihg, }}$ i.e. the pressor response to the test, represents the sympathetic modulation. ${ }^{11}$

Statistical analysis: All the data were tested for normality using the Kolmogorov Smirnov test. Normally distributed data were expressed in Mean \pm Standard deviation (SD). Categorical data like the purpose of using the internet, duration of internet usage, time preference, level of internet addiction, internet addiction status (present/absent), sleep quality (good, poor) were expressed in frequencies. The comparison of parameters between participants with good and poor sleep quality as well as between participants with and without internet addiction was carried out using unpaired student t-test. One way ANOVA was used to determine the significance of differences between total PSQI scores among normal internet users (0-20) as well as those with mild (21-49) and moderate-severe IA (50-100). Post hoc test was done using Tukey adjustment. Pearson's correlation analysis was done to find the correlation of total IA score with total PSQI score, BMI and WHR. Logistic regression analysis was used to determine the significance of the association between PSQI and total IA scores after setting the quality of sleep as the dependent variable and Internet addiction as independent variables after controlling confounding factors such as BMI and WHR. A p value of $<0.05$ was considered statistically significant. 


\section{Results}

The baseline characteristics of the participants are represented in Table 1. Participants were between 18 and 22 years of age. The heart rate and blood pressure of the participants were within the normal range.

Table 2 shows parameters of IA such as purpose, duration, and day or night time preference. $62 \%$ of the participants used the internet for media, and $27.7 \%$ for chatting. Around $65 \%$ of the participants used the internet for $2-4 \mathrm{~h}$ a day. $82.4 \%$ of the participants prefer night time usage of the internet. $87.2 \%$ of the participants had IA (total IA score $>20$ ). Around $73.6 \%$ of the participants had mild IA, and $13.5 \%$ had moderate-severe IA.

Table 3 shows total scores of sleep quality and seven components of PSQI. $66.9 \%$ of the participants had poor sleep quality. The total mean score was around 5.6.

Table 4 shows the comparison of sleep quality and its components between participants with good and bad quality sleepers. The total score, subjective sleep quality, sleep latency, sleep duration, sleep efficiency, sleep disturbance, daytime dysfunction and use of sleep medication were significantly higher in the poor sleep quality group than the good sleeping quality group. Hence all the components of PSQI were significantly higher among participants with poor sleep quality.

Fig. 1 depicts the comparison of total sleep quality score between different levels of IA. The mean PSQI score of normal internet users was $4.2 \pm 2.1$, and Mild IA was $5.6 \pm 2.3$ and moderate-severe was $6.7 \pm 3.1$. There was an increase in total PSQI score in mild IA compared to normal internet users. However, it was not statistically significant. Total PSQI score in moderate to severe IA was significantly higher compared to normal internet users. There was no significant difference between mild and moderate-severe IA. There was a significant positive correlation ( $\mathrm{r}$ $0.224, \mathrm{p}<0.05$ ) between the total PSQI score and total IA score (not shown in the table).

Components of PSQI between participants with IA and without IA are shown in Table 5. Total PSQI was significantly higher among the IA group compared to the without IA. Components distribution parameters such as subjective sleep quality and sleep latency were significantly higher in the participants with IA. There was no significant difference in parameters such as sleep duration and sleep efficiency. Sleep disturbance, sleep medication, and daytime dysfunction was higher in IA participants but was not statistically significant.

Table 6 compares baseline anthropometric parameters, cardiovascular parameters and autonomic parameters between the group with IA and the group without IA. There was no significant difference in BMI between the two groups. WHR was significantly higher among the participants with the IA group. Baseline HR was significantly higher among the IA group but within the normal range. There was no significant difference in SBP, DBP, $\triangle \mathrm{DBP}_{\text {ing }}$ and $\mathrm{E} / \mathrm{I}$ ratio between IA and normal internet user groups. There was no correlation of total internet score with BMI $(r=0.054, p=0.512)$ and WHR $(r=0.106, p=0.198)$ (not shown in the table).

Table 1

Basal characteristics of the study participants.

\begin{tabular}{ll}
\hline Parameters & Mean \pm SD (n = 148) \\
\hline Age (years) & $18.64 \pm 0.87$ \\
Height $(\mathrm{m})$ & $1.65 \pm 0.10$ \\
Weight $(\mathrm{kg})$ & $62.33 \pm 13.44$ \\
BMI $\left(\mathrm{kg} / \mathrm{m}^{2}\right)$ & $22.72 \pm 4.01$ \\
Waist circumference $(\mathrm{cm})$ & $63.71 \pm 24.30$ \\
Hip circumference $(\mathrm{cm})$ & $74.09 \pm 28.45$ \\
WHR & $0.863 \pm 0.072$ \\
Heart rate (beats per minute) & $80.33 \pm 12.85$ \\
Systolic blood pressure (mmHg) & $110.42 \pm 13.31$ \\
Diastolic blood pressure (mmHg) & $69.12 \pm 8.23$ \\
\hline
\end{tabular}

BMI: Body Mass Index; WHR: Waist Hip Ratio.
Table 2

Internet addiction parameters in all the study participants.

\begin{tabular}{lll}
\hline S. no & Parameters & $\begin{array}{l}\text { Number of participants (\%) } \\
(\mathrm{n}=148)\end{array}$ \\
\hline 1. & Purpose of using internet & \\
& Chatting & $41(27.7)$ \\
& Education & $13(8.8)$ \\
& Games & $2(1.4)$ \\
& Media & $92(62.2)$ \\
2 & Duration of internet usage & $23(15.5)$ \\
& $<2$ h per day & $96(64.9)$ \\
& $2-<4$ h per day & $29(19.6)$ \\
& $\geq 4$ h per day & \\
& Time preference & $26(17.6)$ \\
& Day & $122(82.4)$ \\
4 & Night & $19(12.8)$ \\
& Level of Internet Addiction & $109(73.6)$ \\
& Normal $(\leq 20)$ & $19(12.8)$ \\
& Mild $(21-49)$ & $1(0.7)$ \\
& Moderate (50-79) & $129(87.2)$ \\
& Severe $(>80)$ & $19(12.8)$ \\
& Internet Addiction &
\end{tabular}

The data are expressed in number (percentage).

Table 3

Sleep quality parameters based on Pittsburgh Sleep Quality Index scoring.

\begin{tabular}{lll}
\hline S. no & Parameters & $\begin{array}{l}\text { Number of participants (\%) } \\
(\mathrm{n}=148)\end{array}$ \\
\hline 1 & Quality of sleep & \\
& Good $(<5)$ & $49(33.1)$ \\
& Poor $(\geq 5)$ & $99(66.9)$ \\
Component distribution & Score value \\
& Mean \pm SD \\
& Total score & $5.60 \pm 2.50$ \\
& Subjective sleep quality & $0.93 \pm 0.72$ \\
& Sleep latency & $0.86 \pm 0.87$ \\
& Sleep duration & $1.10 \pm 0.69$ \\
& Sleep efficiency & $0.36 \pm 0.83$ \\
& Sleep disturbance & $0.90 \pm 0.42$ \\
& Use of sleep medication & $0.12 \pm 0.42$ \\
& Daytime dysfunction & $1.32 \pm 0.87$
\end{tabular}

The quality of sleep data is expressed in number (percentage). Components of sleep are expressed in Mean \pm SD.

Table 4

Comparison of Components of Pittsburgh Sleep Quality Index between participants with good and poor sleep quality.

\begin{tabular}{llll}
\hline Parameters & $\begin{array}{l}\text { Good sleep quality (n } \\
\text { (49) } \\
\text { Mean } \pm \text { SD }\end{array}$ & $\begin{array}{l}\text { Poor sleep quality (n } \\
\text { 99) } \\
\text { Mean } \pm \text { SD }\end{array}$ & p value \\
\hline $\begin{array}{l}\text { Total score } \\
\text { Subjective sleep }\end{array}$ & $3.04 \pm 1.10$ & $6.87 \pm 1.96$ & $<.001^{*}$ \\
$\quad$ quality & $0.49 \pm 0.54$ & $1.15 \pm 0.69$ & $<.001^{*}$ \\
Sleep latency & $0.33 \pm 0.52$ & $1.12 \pm 0.88$ & $<.001^{*}$ \\
Sleep duration & $0.73 \pm 0.53$ & $1.28 \pm 0.69$ & $<.001^{*}$ \\
Sleep efficiency & $0.00 \pm 0.00$ & $0.55 \pm 0.96$ & $<.001^{*}$ \\
Sleep disturbance & $0.71 \pm 0.46$ & $0.99 \pm 0.36$ & $<.001^{*}$ \\
Use of sleep & $0.02 \pm 0.14$ & $0.17 \pm 0.50$ & $0.038^{*}$ \\
$\quad$ medication & & & $<.001^{*}$ \\
Daytime dysfunction & $0.76 \pm 0.69$ & $1.61 \pm 0.81$ & \\
\hline
\end{tabular}

Unpaired $t$-test was carried out to compare the mean difference between the groups.

*p value $<0.05$ was considered to be significant.

Table 7 shows the comparison of baseline anthropometric parameters, cardiovascular parameters and autonomic parameters between the good sleep quality group and poor sleep quality group. There was no significant difference in BMI and WHR between the good quality and 
12

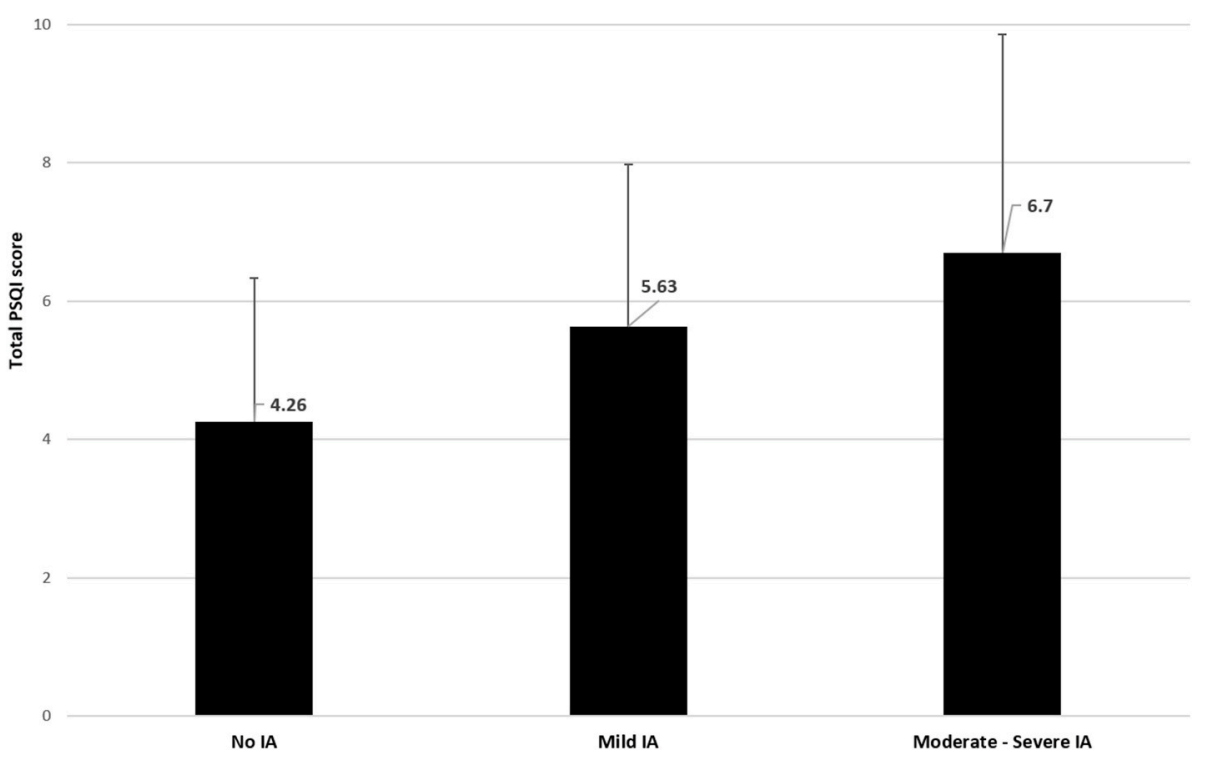

Fig. 1. Comparison of PSQI scores between different grades of Internet Addiction

IA: Internet Addiction.

Mild IA: 21-49; Modern IA-Severe: $>50$.

* Statistical significance between Normal internet users and moderate to severe IA. One way ANOVA was done to compare the total PSQI score between different level of Internet Addiction. $\mathrm{p}<0.05$ was considered as statistically significant.
Table 5

Pittsburgh sleep quality index component distribution between participants with and without internet addiction.

\begin{tabular}{|c|c|c|c|}
\hline PSQI scores & $\begin{array}{l}\text { Internet addiction } \\
\text { present }(I A>20)(n=129) \\
\text { Mean } \pm S D\end{array}$ & $\begin{array}{l}\text { Internet addiction } \\
\text { absent }(I A \leq 20)(n=19) \\
\text { Mean } \pm S D\end{array}$ & $\begin{array}{l}\mathrm{p} \\
\text { value }\end{array}$ \\
\hline Total score & $5.80 \pm 2.50$ & $4.26 \pm 2.08$ & $0.012 *$ \\
\hline $\begin{array}{l}\text { Subjective sleep } \\
\text { quality }\end{array}$ & $0.97 \pm 0.70$ & $0.63 \pm 0.76$ & $0.049 *$ \\
\hline Sleep latency & $0.95 \pm 0.87$ & $0.26 \pm 0.56$ & $0.001 *$ \\
\hline Sleep duration & $1.10 \pm 0.72$ & $1.11 \pm 0.46$ & 0.979 \\
\hline Sleep efficiency & $0.35 \pm 0.79$ & $0.47 \pm 1.02$ & 0.540 \\
\hline $\begin{array}{l}\text { Sleep } \\
\text { disturbance }\end{array}$ & $0.92 \pm 0.41$ & $0.74 \pm 0.45$ & 0.069 \\
\hline $\begin{array}{l}\text { Use of sleep } \\
\text { medication }\end{array}$ & $0.13 \pm 0.44$ & $0.05 \pm 0.23$ & 0.444 \\
\hline $\begin{array}{l}\text { Daytime } \\
\text { dysfunction }\end{array}$ & $1.37 \pm 0.88$ & $1.00 \pm 0.74$ & 0.081 \\
\hline
\end{tabular}

Unpaired $t$-test was done to compare the mean difference between the groups. *p value $<0.05$ was considered to be significant.

poor sleep quality group. Diastolic blood pressure in isometric handgrip (vasoconstrictor response) was significantly higher in the poor sleep quality group than the good sleep quality group $(\mathrm{p}<.001)$. Other parameters such as HR, SBP, DBP and E/I ratio were not significantly different between the two groups.

Table 8 shows the association between internet usage and sleep quality. 129 participants had internet addiction (IA $>20$ ), and out of them, $70.5 \%$ of the participants had poor sleep quality. After controlling the possible confounding variables such as BMI and WHR, logistic regression analysis revealed a significant association between sleep quality and internet addiction ( $\chi^{2}: 5.680$; OR: 3.293; CI: 0.205-2.178; P $<0.05$ ). Individuals with IA had three times the likelihood of having poor sleep quality.

\section{Discussion}

In this study, we assessed the level of IA, sleep quality, baseline cardiovascular parameters (SBP, DBP and heart rate), parasympathetic reactivity and sympathetic reactivity in undergraduate medical
Table 6

Comparison of baseline cardiovascular and autonomic function variables between participants with and without internet addiction.

\begin{tabular}{llll}
\hline Parameters & $\begin{array}{l}\text { Internet addiction } \\
\text { present }(\mathrm{n}=129) \\
\text { Mean } \pm \mathrm{SD}\end{array}$ & $\begin{array}{l}\text { Internet addiction } \\
\text { absent }(\mathrm{n}=19) \\
\text { Mean } \pm \mathrm{SD}\end{array}$ & $\begin{array}{l}\mathrm{p} \\
\text { value }\end{array}$ \\
\hline BMI & $22.88 \pm 4.02$ & $21.66 \pm 3.86$ & 0.219 \\
WHR & $0.868 \pm 0.073$ & $0.828 \pm 0.053$ & $0.022^{*}$ \\
$\begin{array}{l}\text { Heart rate (beats per } \\
\text { minute) }\end{array}$ & $86.74 \pm 11.02$ & $79.39 \pm 12.87$ & $0.019^{*}$ \\
$\quad \begin{array}{l}\text { Systolic Blood } \\
\text { pressure (mm Hg) }\end{array}$ & $110.43 \pm 13.04$ & $110.37 \pm 15.42$ & 0.986 \\
$\begin{array}{c}\text { Diastolic blood } \\
\text { pressure (mm Hg) }\end{array}$ & $68.65 \pm 7.85$ & $72.32 \pm 10.15$ & 0.070 \\
$\begin{array}{l}\Delta \text { DBP } \text { ihg (mm Hg) } \\
\text { E: } \text { I Ratio }\end{array}$ & $20.22 \pm 7.85$ & $19.37 \pm 6.71$ & 0.655 \\
\hline
\end{tabular}

$\triangle \mathrm{DBP}_{\text {ihg }}$ : Difference between highest DBP recorded during sustained handgrip and baseline DBP.

E: I ratio: Ratio of longest RR interval during expiration to the shortest RR interval during inspiration.

Unpaired $t$-test was done to compare the mean difference between the groups. $\mathrm{p}$ value $<0.05$ was considered to be significant.

students.

We observed that internet access for media usage is more than other purposes like chatting, education and games. In the present study, around $65 \%$ of participants reported internet usage of $2-4 \mathrm{~h}$ per day, and $19.6 \%$ reported internet usage of more than $4 \mathrm{~h}$ per day. Further, the preference for internet usage at night-time was more than daytime. Our study observed that $87.2 \%$ of the participants were addicted to the internet. Similar results were reported by several other studies showing significant IA among the students. ${ }^{12-14}$ However, we document a significant percentage of internet addicted participants.

According to the PSQI score, $66.9 \%$ of our study participants had demonstrated poor sleeping quality. Further, we observed that IA is correlated with poor sleeping quality indicating the negative impact of internet addiction on sleeping quality. Logistic regression analysis between sleep quality and internet addiction revealed a significant association. There was three times likelihood of developing poor sleep quality with internet addiction. Lin et al. assessed the association 
Table 7

Comparison of basal characteristics and autonomic function variables between the group of participants with good sleep quality and group of participants with poor sleep quality.

\begin{tabular}{|c|c|c|c|}
\hline \multirow[t]{2}{*}{ Parameters } & \multicolumn{2}{|c|}{ Pittsburgh sleep quality index } & \multirow[b]{2}{*}{$\begin{array}{l}\mathrm{p} \\
\text { value }\end{array}$} \\
\hline & $\begin{array}{l}\text { Good sleep quality } \\
(\mathrm{n}=49) \\
\text { Mean } \pm \text { SD }\end{array}$ & $\begin{array}{l}\text { Poor sleep quality } \\
(\mathrm{n}=99) \\
\text { Mean } \pm \mathrm{SD}\end{array}$ & \\
\hline BMI & $23.11 \pm 4.14$ & $22.53 \pm 3.95$ & 0.408 \\
\hline WHR & $0.871 \pm 0.072$ & $0.859 \pm 0.073$ & 0.370 \\
\hline $\begin{array}{l}\text { Heart rate (beats per } \\
\text { minute) }\end{array}$ & $80.98 \pm 12.44$ & $80.01 \pm 13.10$ & 0.667 \\
\hline $\begin{array}{l}\text { Systolic Blood pressure } \\
\text { (mm Hg) }\end{array}$ & $112.73 \pm 13.79$ & $109.27 \pm 12.99$ & 0.137 \\
\hline $\begin{array}{l}\text { Diastolic blood pressure } \\
\text { (mm Hg) }\end{array}$ & $70.35 \pm 9.16$ & $68.52 \pm 7.71$ & 0.204 \\
\hline$\Delta \mathrm{DBP}_{\text {ihg }}(\mathrm{mm} \mathrm{Hg})$ & $17.32 \pm 4.06$ & $21.48 \pm 8.66$ & $<.001^{*}$ \\
\hline E: I ratio & $1.44 \pm 0.15$ & $1.45 \pm 0.14$ & 0.506 \\
\hline
\end{tabular}

Unpaired $t$-test was done to compare the mean difference between the groups. $\mathrm{p}$ value $<0.05$ was considered to be significant. $\triangle \mathrm{DBP}_{\text {ihg }}$ : Difference between highest DBP recorded during sustained handgrip and baseline DBP. E/I ratio: Expiratory: inspiratory ratio.

between sleep quality and internet addiction among female college students and revealed a significant association. ${ }^{15}$ Further, Cheng SH et al. documented that poor lifestyle habits and overuse of the internet impair sleeping quality leading to poor academic performance and absenteeism. ${ }^{14}$ In the same line of this study, another report also demonstrated a significant association between internet addiction and poor sleeping quality among children in the age group of $10-20$ years from china. ${ }^{16}$

Regarding the time preference for internet usage, $122(82.4 \%)$ reported overuse of the internet during night-time. Similarly Hershner et al. ${ }^{17}$ and Gradisar et al. ${ }^{18}$ also reported more prevalence of using technology around bedtime. Researchers have identified the negative impact of using light-emitting-device at bedtime on sleep because of its association with cognitive stimulation. ${ }^{19-23}$ The poor sleeping quality among the students in our study could be mainly attributed to the night-time use of light-emitting devices.

Kocas et al., in their study, reported that the time spent in front of any screen affects the sleep preparation process of an individual. Also, the light and sound from those screens (computers, mobile phones, or tablet) may influence the fluctuations in hormones involved in sleep. Hence, longtime screen exposure during bedtime interrupt the sleep rhythm, delay the transition of sleep, reduce sleep time, and spoil the sleep quality leading to frequent breaks while sleeping. ${ }^{24}$ In addition to cognitive impairment, difficulty in learning, perception and memory, sleep deprivation increases the risk for various diseases, including diabetes, cancer, and cardiovascular diseases. ${ }^{25-27}$

Resting heart rate is an indicator of cardiac autonomic function and a predictor of cardiovascular disease and mortality. ${ }^{28}$ Confirming our hypothesis, we found significantly increased resting heart rate in participants with internet addiction. In our study, we found there was a significant increase in diastolic rise in blood pressure during isometric handgrip. Therefore, we hypothesize that the participants had a decreased vagal and increased adrenergic modulation. We did not find any significant difference in other autonomic reactivity tests. Nevertheless, our findings emphasize that a significant percentage of undergraduate medical students could be addicted to internet usage, resulting in poor sleep quality, thereby resulting in sympathetic predominance and decreased vagal modulation.

Together, our findings suggest that the probable cause for poor sleeping quality in IA could be psychological stress induced by internet overuse, thereby resulting in sympathetic predominance, which impairs sleeping quality. In support of our suggestion, Alavi et al. reported the association of internet overuse with mental health problems like depression, anxiety, somatization, aggression, phobias and psychosis. ${ }^{29}$ But sufficient evidence on the effect of internet addiction on cardiovascular autonomic health, an early risk predictor, is sparse. In the wake of this, our study can be considered a preliminary report to sensitize about the adverse effects of internet overuse on sleep quality and emphasize its long-term hazardous effect on cardiovascular health, paving the way for further research on this impending health hazard.

Conclusion: We conclude that there is internet overuse among undergraduate medical students, especially at night-time, which is associated with poor sleep quality in them, thereby altering autonomic modulation in the form of increased sympathetic and decreased vagal modulation.

Limitation of the study: We did not assess the psychological stress in our study population. Another limitation is the modest sample size of the present study. Hence, we suggest further studies involving students of various other professionals to explain the association between internet overuse and sleep quality and psychological assessment in a larger sample size.

\section{Author contributions}

All the authors have accepted responsibility for the entire content of this manuscript and approved its submission.

\section{Research funding}

Nil.

\section{Informed consent}

Informed consent was obtained from all individuals included in this study.

\section{Ethical approval}

Research involving human subjects complied with all relevant national regulations, institutional policies and is in accordance with the tenets of the Helsinki Declaration (as revised in 2013), and has been approved by the authors' institutional review board of Human Ethics Committee of Jawaharlal Institute of Postgraduate Medical Education

Table 8

Association between internet addiction and sleep quality.

\begin{tabular}{|c|c|c|c|c|c|c|c|}
\hline \multirow{2}{*}{$\begin{array}{l}\text { PSQI } \\
\text { IA }\end{array}$} & & \multicolumn{2}{|l|}{ PSQI } & \multirow[t]{2}{*}{ Total Score } & \multirow[t]{2}{*}{ Chi square Value } & \multirow[t]{2}{*}{ OR $(95 \% \mathrm{CI})$} & \multirow[t]{2}{*}{$\mathrm{P}$ value } \\
\hline & & Poor sleep quality $(\geq 5)$ & Good sleep quality $(<5)$ & & & & \\
\hline \multirow[t]{3}{*}{ IA } & Present $(>20)$ & 91 & 38 & 129 & 5.680 & $3.293(0.205-2.178)$ & $0.018^{*}$ \\
\hline & Absent $(\leq 20)$ & 8 & 11 & 19 & & & \\
\hline & Total & 99 & 49 & 148 & & & \\
\hline
\end{tabular}

$* \mathrm{P}<0.05$ was consideredsignificant.

Association between internet addiction and sleep quality was analyzed using Logistic Regression.

OR: Odd's Ratio; CI: Confidence Interval; PSQI: Pittsburgh Sleep Quality Index.

IA: Internet Addiction. 
and Research, Puducherry.

\section{Source(s) of support}

The study is approved and supported by Indian Council of Medical Research (ICMR)

Presentation at a meeting

Nil.

\section{Declaration of competing interest}

Authors state no conflict of interest.

\section{Acknowledgement}

The authors are thankful to all the students who participated in the study, and we thank Indian Council of Medical Research for approving our project under short term studentship -2018 .

\section{References}

1 Capetillo-Ventura N, Juárez-Treviño M. Internet addiction in university medical students. Med Univ. 2015;17(67):88-93.

2 Orsal O, Orsal O, Unsal A, Ozalp SS. Evaluation of internet addiction and depression among university students. Procedia - SocBehav Sci. 2013;82:445-454.

3 Fatehi F, Monajemi A, Sadeghi A, Mojtahedzadeh R, Mirzazadeh A. Quality of life in medical students with internet addiction. Acta Med Iran. 2016;54(10):662-666.

4 AzwaAmbad Sylvia Nabila, Kalimin KhairiahMazdiah, Amir Ku Mohd, Yusof Aizat Ku. The effect of internet addiction on students' emotional and academic performance. e-Academia Journal. 2017;6(1):86-98.

$5 \mathrm{Lu} \mathrm{K}$, Chen J, Wu S, Chen J, Hu D. Interaction of sleep duration and sleep quality on hypertension prevalence in adult Chinese males. J Epidemiol. 2015;25(6):415-422.

6 Werner GG, Ford BQ, Mauss IB, Schabus M, Blechert J, Wilhelm FH. High cardiac vagal control is related to better subjective and objective sleep quality. Biol Psychol. 2015;106:79-85.

7 Krishnamurthy S, Chetlapalli S. Internet addiction: prevalence and risk factors: a cross-sectional study among college students in Bengaluru, the Silicon Valley of India. Indian J Publ Health. 2015;59(2):115-121.

8 Misra A, Chowbey P, Makkar BM, et al. Consensus statement for diagnosis of obesity, AbdominalObesity and the metabolic syndrome for asian Indians andRecommendations for physical activity, medical and SurgicalManagement. I Assoc Phys India. 2009;57:163-170.

9 Geneva: World Health Organization. World Health Organization (WHO). Waist Circumference and Waist-Hip Ratio. Report of WHO Expert Consultation. 2008.
10 Mathias CJ, Bannister R. Investigation of autonomic disorders. In: Mathias CJ, Bannister R, eds. Autonomic Failure: A Textbook of Clinical Disorders of the Autonomic Nervous System. fourth ed. Great Britain: Oxford University Press; 1999:169-195.

11 Low PA. Laboratory evaluation of autonomic function. Suppl Clin neurophysiol. 2004; 57:358-368.

12 Sharma A, Sahu R, Kasar P, Sharma R. Internet addiction among professional courses students: a study from central India. Int J Med Sci Publ Health. 2014;3(9):1069-1073.

13 Bagdey P, Adikane H, Narlawar U, Dhage D, Surwase K, Kaware A. A cross sectional study of prevalence of internet addiction and its association with mental health among college going students in Nagpur city. Int. J.Community Med.public health. 2018;5(4):1658-1665.

14 Cheng SH, Shih CC, Lee IH, et al. A study on the sleep quality of incoming university students. Psychiatr Res. 2012;197(3):270-274.

15 Lin PH, Lee YC, Chen KL, Hsieh PL, Yang SY, Lin YL. The relationship between sleep quality and internet addiction among female college students. Front Neurosci. 2019 Jun 12;13:599.

16 Cheung LM, Wong W. The effects of insomnia and internet addiction on depression in Hong Kong Chinese adolescents: an exploratory cross-sectional analysis. J Sleep Res. 2011;20:311-317.

17 Hershner S, Chervin R. Causes and consequences of sleepiness among college students. Nat Sci Sleep. 2014;6:73-84.

18 Gradisar M, Wolfson AR, Harvey AG, Hale L, Rosenberg R, Czeisler CA. The sleep and technology use of Americans: findings from the national sleep foundation's 2011 sleep in America poll. J.Clin. Sleep .Med. 2013;12(9):1291-1299.

19 Heo J-Y, Kim K, Fava M, et al. Effects of smartphone use with and without blue light at night in healthy adults: a randomized, double-blind, cross-over, placebocontrolled comparison. J Psychiatr Res. 2017;87:61-70.

20 Grønli J, Byrkjedal IK, Bjorvatn B, Nødtvedt, Hamre B, Pallesen S. Reading from an iPad or from a book in bed: the impact on human sleep. A randomized controlled crossover trial. Sleep Med. 2016;2:86-92.

21 Rahman SA, Hilaire M A St, Lockley SW. The effects of spectral tuning of evening ambient light on melatonin suppression, alertness, and sleep. Physiol Behav. 2017; 177:221-229.

22 Touitou Y, Touitou D, Reinberg A. Disruption of adolescents' circadian clock: the vicious circle of media use, exposure to light at night, sleep loss and risk behaviors. J Physiol Paris. 2016;110(4):467-479.

23 Bedrosian TA, Nelson RJ. Timing of light exposure affects mood and brain circuits. Transl Psychiatry. 2017;7(1):e1017-e.

24 Kocas Fazıl, Sasmaz Tayyar. Internet addiction increases poor sleep quality among high school students. Turk J Public Health. 2018;16(3):167-177.

25 Reading P. Normal versus Abnormal Sleep, Chapter 1. ABC of Sleep Medicine. John Wiley\&Soons, Ltd; 2013.

26 Fulke P, Vaughan S. Sleep deprivation: Causes, effects, and treatment. Physiology and Behavior. In: Natale V. Fabbri M. Esposito MJ. Martoni M. Tonetti L. Cicogna PC. Cognitive performance during a night without sleep. Nova Science Publishers. Italy: 2009.

27 Peltzer K, Pengpid S. Nocturnal sleep problems among university students from 26 countries. Sleep Breath. 2015;19:499-508.

28 Kannel WB, Kannel C, Paffenbarger Jr RS, Cupples LA. Heart rate and cardiovascular mortality: the Framingham Study. Am Heart J. 1987;113:1489-1494.

29 Alavi SS, Maracy MR, Jannatifard F, Eslami M. The effect of psychiatric symptoms on the internet addiction disorder in Isfahan's University students. J Res Med Sci. 2011; 16(6):793-800. 